\title{
Provider Attitudes and Screening Practices Following Changes in Breast and Cervical Cancer Screening Guidelines
}

\author{
Jennifer S. Haas, MD, MSc ${ }^{1,2,7,9}$, Brian L. Sprague, $P h D^{3}$, Carrie N. Klabunde, $P h D^{5}$, \\ Anna N. A. Tosteson, ScD ${ }^{4}$, Jane S. Chen, $S C B^{7}$, Asaf Bitton, MD, MPH ${ }^{1,2}$, \\ Elisabeth F. Beaber, PhD, MPH', Tracy Onega, PhD, MA, MS', Jane J. Kim, PhD', \\ Charles D. MacLean, $M D^{3}$, Kimberly Harris, $M M^{7}$, Phillip Yamartino, $B S^{8}$, Kathleen Howe, $A A^{3}$, \\ Loretta Pearson, MPhil', Sarah Feldman, MD, MPH ${ }^{1,2}$, Phyllis Brawarsky, $\mathrm{MPH}^{7}$, and Marilyn $M$. \\ Schapira, MD, MPH' on behalf of the PROSPR (Population-based Research Optimizing \\ Screening through Personalized Regimens) Consortium
}

\footnotetext{
'Brigham and Women's Hospital, Boston, MA, USA; ${ }^{2}$ Harvard Medical School, Boston, MA, USA; ${ }^{3}$ University of Vermont, Burlington, VT, USA; ${ }^{4}$ Geisel School of Medicine at Dartmouth and Norris Cotton Cancer Center, Lebanon, NH, USA; ${ }^{5}$ Office of Disease Prevention, Office of the Director, National Institutes of Health, Bethesda, MD, USA; ${ }^{6}$ Fred Hutchinson Cancer Research Center, Seattle, WA, USA; ${ }^{7}$ Harvard T.H. Chan School of Public Health, Boston, MA, USA; ${ }^{8}$ University of Pennsylvania and the Philadelphia VA Medical Center, Philadelphia, PA, USA; ${ }^{9}$ Division of General Medicine and Primary Care, Brigham and Women's Hospital, Boston, MA, USA.
}

\begin{abstract}
BACKGROUND: Changes to national guidelines for breast and cervical cancer screening have created confusion and controversy for women and their primary care providers.

OBJECTIVE: To characterize women's primary health care provider attitudes towards screening and changes in practice in response to recent revisions in guidelines for breast and cervical cancer screening.

DESIGN, SETTING, PARTICIPANTS: In 2014, we distributed a confidential web and mail survey to 668 women's health care providers affiliated with the four clinical care networks participating in the three PROSPR (Populationbased Research Optimizing Screening through Personalized Regimens) consortium breast cancer research centers (385 respondents; response rate $57.6 \%$ ).

MAIN MEASURES: We assessed self-reported attitudes toward breast and cervical cancer screening, as well as practice changes in response to the most recent revisions of the U.S. Preventive Services Task Force (USPSTF) recommendations.
\end{abstract}

KEY RESULTS: The majority of providers believed that mammography screening was effective for reducing cancer mortality among women ages 40-74 years, and that Papanicolaou (Pap) testing was very effective for women ages 21-64 years. While the USPSTF breast and cervical cancer screening recommendations were widely perceived by the respondents as influential, 75.7 and $41.2 \%$ of providers (for mammography and cervical cancer screening, respectively) reported screening practices in excess of those recommended by USPSTF. Provider-reported barriers to concordance with guideline recommendations included: patient concerns (74 and $36 \%$ for breast and cervical, respectively), provider disagreement with the recommendations (50 and $14 \%$ ), health system measurement of a provider's screening practices that use conflicting measurement criteria (40 and $21 \%$ ), concern about

Received March 5, 2015

Revised May 28, 2015

Accepted June 5, 2015

Published online July 1, 2015 malpractice risk (33 and $11 \%$ ), and lack of time to discuss the benefits and harms with their patients (17 and $8 \%$ ). CONCLUSIONS: Primary care providers do not consistently follow recent USPSTF breast and cervical cancer screening recommendations, despite noting that these guidelines are influential.

KEY WORDS: breast cancer screening; cervical cancer screening; provider practice patterns; primary care; clinical practice guidelines.

J Gen Intern Med 31(1):52-9

DOI: $10.1007 / \mathrm{s} 11606-015-3449-5$

(C) Society of General Internal Medicine 2015

\section{BACKGROUND}

Changes to national screening guidelines for breast and cervical cancer screening have created confusion and controversy for women and their primary care providers. ${ }^{1,2}$ In 2009 , the U.S. Preventive Services Task Force (USPSTF) issued revised breast cancer screening guidelines for average-risk, asymptomatic women recommending that 1) women discuss when to begin screening with their health care providers, 2) most average-risk women should begin screening at age 50 instead of age 40 , and 3 ) the frequency of screening for women ages 50-74 should decrease from annually to every 2 years. ${ }^{3,4}$ These guidelines, in part, reflect evidence from breast cancer simulation models demonstrating that biennial screening of women ages 50-74 years maximizes the potential benefits of screening, while minimizing such harms as false-positive results and unnecessary biopsies. ${ }^{5}$ Notably, the 2009 USPSTF guidelines conflict with those of other influential groups, including the American Cancer Society (ACS), ${ }^{6}$ American College of Obstetricians and Gynecologists (ACOG), ${ }^{7}$ and American College of Radiology, ${ }^{8}$ all of which recommend annual screening beginning at age 40 .

In 2012, the USPSTF and ACOG introduced significant revisions to their cervical cancer screening guidelines. ${ }^{9,10}$ 
These recommendations included initiating screening no earlier than age 21, regardless of sexual behavior, and screening with Papanicolaou (Pap) testing every 3 years until age 30, with the choice of adding human papillomavirus (HPV) cotesting to Pap testing every 5 years or continuation of Pap tests alone every 3 years until age 65 (in previously screened women with normal results). These revisions signaled an important transition in screening guidelines from a "one size fits all" approach (e.g., screen every woman every year) to a more individualized approach based on personal risk and prior screening results.

The increased complexity of risk-based screening protocols places greater demands on the health care system charged with implementing them. ${ }^{11}$ Not surprisingly, guideline changes have created complexity and uncertainty for primary care providers, many of whom practice in health care systems with varying infrastructure for implementation. The revised USPSTF mammography screening guidelines have also been met with substantial lay concerns about care rationing, ${ }^{12}$ and have fostered considerable debate among experts. ${ }^{2}$

Little is known about how provider attitudes and practices have changed since the release of these revised recommendations. Prior to the revisions, a national survey conducted in 2007 showed that the majority of U.S. primary care physicians routinely recommended screening mammography for women in their $40 \mathrm{~s}$, and over $90 \%$ recommended annual screening mammography for women ages 50 and older. ${ }^{13,14}$ This survey also documented primary care physicians' preferences for annual Pap testing for most women. Although more recent national data are not available, a 2012 survey of physicians from the University of Pittsburgh found that gynecologists were more likely than internists or family physicians to offer annual versus biennial mammography testing. ${ }^{15}$ Many of these providers reported cervical cancer screening practices inconsistent with the 2009 ACOG screening guidelines. ${ }^{16}$ Given the ongoing debate about the most appropriate timing of breast and cervical cancer screening, it is important to understand how primary care providers' screening practices have been affected by guideline changes, particularly given the shift in larger health care settings towards more team-based care involving non-physician clinicians. ${ }^{17}$ This is particularly timely given the April 2015 release of a draft update of the USPSTF guidelines for breast cancer screening for public comment; the draft recommendations are consistent with the 2009 version.

This study was conducted as part of the NCI-funded Population-Based Research Optimizing Screening through Personalized Regimens (PROSPR) consortium. The overall aim of PROSPR is to conduct multi-site, coordinated, transdisciplinary research to evaluate and improve cancer screening processes. Within the PROSPR consortium sites focused on breast cancer screening, we conducted a survey of women's primary health care providers to understand how the revised guidelines for breast and cervical cancer screening may have altered their attitudes and clinical practice. Their perspectives can be informative in interpreting cancer screening utilization data.

\section{METHODS}

\section{Overview}

In the fall of 2014, we conducted a confidential Web and mail survey of women's health care providers affiliated with the four clinical care networks within the three PROSPR breast cancer research centers. The survey included questions on attitudes towards breast and cervical cancer screening, and changes in the use of screening since the most recent revisions to the USPSTF screening recommendations.

\section{Setting and Participants}

Women's primary health care providers who practiced in the clinical care networks affiliated with Brigham and Women's Hospital (BWH), Boston, MA; Dartmouth-Hitchcock Health System (DH), Lebanon, NH; the University of Pennsylvania (PENN), Philadelphia, PA; and those practicing in the state of Vermont (VT) were the target population. ${ }^{18}$ More information about PROSPR, the participating sites, and publications to date can be found on the PROSPR website (http:// healthcaredelivery.cancer.gov/prospr/). For BWH, DH and PENN, we included providers who had ordered or were expected to order at least five mammograms among those recorded in the existing PROSPR consortium database. In VT, providers were randomly sampled from an annual census of primary care providers collected for workforce analyses by the Vermont Area Health Education Centers Program. At all sites, we included currently practicing providers with a designated specialty of general internal medicine, family medicine, or gynecology, including physicians (both MDs and DOs), physician assistants (PAs), certified nurse midwives (CNMs), and nurse practitioners (NPs). Providers who were in residency training were excluded. The study protocol was approved by the institutional review boards of the participating institutions.

\section{Recruitment Protocol}

The survey was fielded among 668 primary care providers in September through December of 2014. Because of varying health system characteristics and IRB approvals, the number of contact attempts and mode of survey dissemination differed across sites. At two sites, providers received an email with a link to a Web-based survey at weeks 0 and 1 , a mailed version of the survey at weeks 2 and 4 , and a final email with a link to a Web-based survey at week 6 . The second site received another paper version at week 8 . Providers at the third site received an email with a link to the electronic survey at weeks 0,1 and 8 , and mailed versions at weeks 2 and 9 . The fourth site did not 
have access to provider email addresses and mailed paper surveys at weeks $0,2,6$ and 10 . At the time of first contact, providers received a code for a $\$ 50$ gift card to an online retailer as an incentive for participation.

\section{Survey Content and Measures}

The questionnaire content was adapted from NCI's National Survey of Primary Care Physicians' Cancer Screening Recommendations and Practices, last fielded in 2007. ${ }^{13,14,19}$ Provider characteristics and experience were measured by age, gender, specialty, medical school affiliation (as a proxy for working in a setting where there was teaching of medical students and residents, as teaching responsibilities may be associated with greater familiarity with guidelines and evidence-based practice), and number of office visits during a typical week. We also asked providers about the characteristics of their main practice site, including practice location (e.g., non-hospital-based, hospital-based, or community health center), achievement of National Committee for Quality Assurance (NCQA) recognition as a medical home, and the number of full- or part-time physicians in the practice. Providers were asked to rate how effective they believed that breast and cervical cancer screening is in reducing cancer mortality for average-risk women, how often they recommended screening for most average-risk, asymptomatic women, which screening guidelines were most influential to their practice, and whether their screening practices for each age group had changed since the revisions of the USPSTF recommendations for breast cancer screening in 2009 and cervical cancer screening in 2012. Providers who reported no change in practice were further asked about factors that influenced their decision. Finally, providers were asked how often their patients requested more frequent screening than the current guideline recommendations.

\section{Data Analysis}

We created summary measures of whether a provider recommended breast and cervical cancer screening in excess of the guidelines (i.e., measures for breast and cervical cancer were created separately). ${ }^{4,10}$ We evaluated the influence of provider and practice characteristics on provider attitudes (perceived effectiveness and influence of guidelines) about screening and self-reported practice. Sample characteristics and screening practices were summarized with descriptive statistics. We developed multivariate logistic regression models to examine the relationship between provider and practice characteristics and recommendation for breast and cervical cancer screening in excess of the guidelines. Variables selected for the models included those considered a priori to be important factors. The variables included were provider age, sex, specialty, number of office visits per week, and practice characteristics including NCQA recognition as a medical home, practice type and size, and clinical network. We calculated odds ratios (OR) and $95 \%$ confidence intervals (CI).

\section{RESULTS}

\section{Study Population}

Of 668 eligible providers, 385 (57.6\%) completed the survey. There were no significant differences in response rates by site $(p=0.10)$ or provider specialty $(p=0.13)$, but women were more likely to respond then men $(62.7 \%$ vs. $48.5 \%, p<0.001)$. Most respondents had a medical school affiliation. There were more general internists than family physicians, gynecologists, or PAs/NPs/ CNMs. Half of the providers practiced in an NCQArecognized medical home. Participant characteristics are summarized in Table 1.

\section{Attitudes Towards Guidelines}

The USPSTF screening recommendations were most commonly described by respondents as very or somewhat influential $(91 \%$ for breast and $90 \%$ for cervical cancer), followed by ACS guidelines (81.9 and 77.1\%, respectively), and ACOG guidelines (77.5 and $88.1 \%$ ).

Table 1 Survey Participants $(n=385)$

\begin{tabular}{lr}
\hline \hline Provider characteristics & N (\%) \\
\hline Age: & \\
$<40$ years & $96(25.8)$ \\
40-49 years & $115(30.9)$ \\
$50-59$ years & $93(25.0)$ \\
60+years & $68(18.3)$ \\
Female & $270(70.1)$ \\
Provider specialty: & $78(21.0)$ \\
Family medicine (MD/ DO) & $171(46.0)$ \\
General internal medicine (MD/ DO) & $77(20.7)$ \\
Gynecology (MD/ DO) & $46(12.4)$ \\
Physician assistant, nurse practitioner, & \\
certified nurse midwife & $308(82.8)$ \\
Medical school affiliation (=yes) & $65(17.5)$ \\
Typical week, no. of office visits & $109(29.4)$ \\
<=25 & $121(32.6)$ \\
26-50 & $76(20.5)$ \\
51-75 & \\
$76+$ & $117(30.4)$ \\
Clinical network site & $76(19.7)$ \\
Brigham and Women's Hospital & $104(27.0)$ \\
Dartmouth-Hitchcock & $88(22.9)$ \\
University of Pennsylvania & \\
University of Vermont & $181(49.2)$ \\
Main practice characteristics & \\
National Committee for Quality Assurance & \\
(NCQA)-recognized medical home & \\
Practice type: & $207(55.8)$ \\
Non-hospital-based office & $138(37.2)$ \\
Hospital-based office & $26(7.0)$ \\
Community health center & $76(20.4)$ \\
Number of full- or part-time physicians in practice & $141(37.8)$ \\
$<5$ & $96(25.7)$ \\
5-10 & $37(9.9)$ \\
11-20 $21-50$ & $23(6.2)$ \\
50+ & \\
& \\
\hline &
\end{tabular}


The majority of providers believed that mammography screening was effective for women aged 40-74 years, Pap testing was effective for women ages 21-64 years, and HPV and Pap co-testing was effective for women ages 30-64 years (Fig. 1).

\section{Breast Cancer Screening}

Seventy-five percent of providers reported mammography screening practices in excess of USPSTF recommendations for at least one age group (Table 2a). Providers were most likely to report excessive screening use for women ages 50-74, for whom $65.4 \%$ reported that they recommended annual mammography rather than biennial screening $(21.0 \%)$ or that they discussed interval options with patients (13.1\%). Also in excess of the USPSTF recommendations, $40 \%$ of providers reported that they recommended regular mammography annually (31.9\%) or biennially (8.4\%), for women ages 40-49. In multivariate models, gynecologists and non-physicians were more likely than general internists to report overuse, and those who practiced in a hospital-based setting (OR $0.36 ; 95 \%$ CI $0.18-0.74)$ or a community health center $(0.29 ; 0.09-0.92)$ were less likely than those who practiced in a non-hospital-based office to report overuse (Table 3).

\section{Cervical Cancer Screening}

Forty-one percent of providers reported cervical cancer screening in excess of the USPSTF guidelines for at least one age group (Table $2 \mathrm{~b}$ ). While only $2.9 \%$ of providers reported screening women under age 21 who were not sexually active, $20.7 \%$ reported that they screened sexually active women in this age group. Twenty-two percent reported annual screening of women in their $20 \mathrm{~s}$, as opposed to screening every 3 years. In multivariate models, we found that gynecologists were less likely than general internists $(0.29 ; 0.13-0.65)$ to report cervical cancer screening in excess of the USPSTF guidelines (Table 3). Providers in hospital-based practices were less likely than those in a non-hospital-based setting to recommend screening in excess of the guidelines, as were providers who were less than 40 years old.

\section{Changes in Practice}

One-third of providers reported that their mammography screening practices for women ages 50-74 had not changed at all since the guideline revisions and that their practices were not concordant with the guidelines (Fig. 2). Among this group, the following reasons were cited: patient concern about the guidelines $(74 \%)$, provider not agreeing with the guidelines (50\%), health system measurement of a provider's screening practices measures that used conflicting criteria (40\%), malpractice risk $(33 \%)$, and inadequate time to discuss benefits and harms $(17 \%)$.

The majority of providers reported that their cervical cancer screening practices had changed since the guideline revisions (Fig. 2). The few providers who reported that their practices had not changed despite being nonconcordant with the guidelines cited the following reasons: patient concern about the guidelines (36\%), health system measurement of a provider's screening practices that use different criteria $(21 \%)$, provider not agreeing

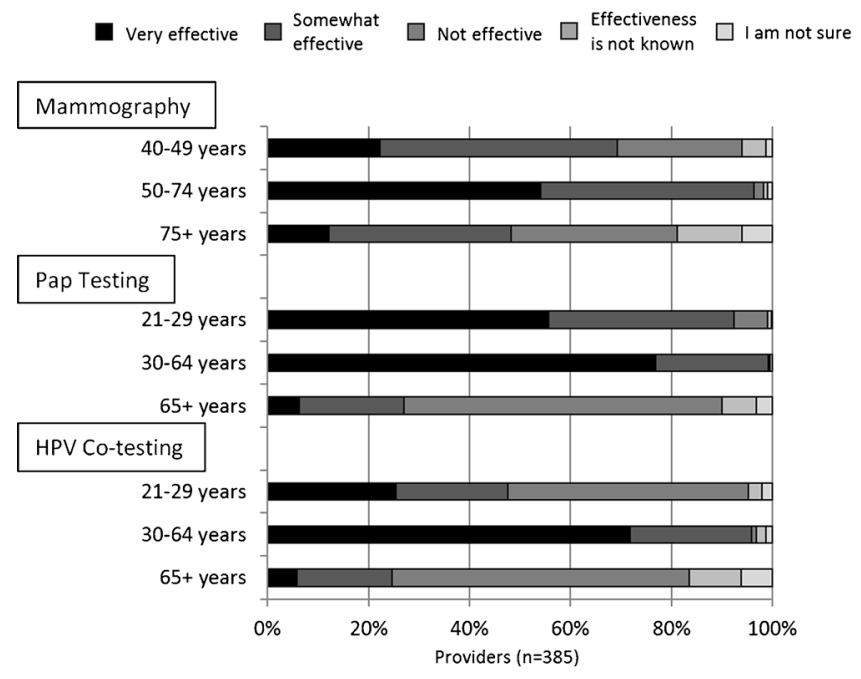

Fig. 1 Provider report of cancer screening efficacy by modality and age group 
Table 2 Self-Reported Care of Average-Risk, Asymptomatic Women Compared to the USPSTF Guidelines

2a. Mammography:

Overall concordance across all age groups: $19.8 \%$

Screening in excess of the guidelines for at least one age group: $75.7 \%$

\begin{tabular}{|l|c|c|c|c|}
\hline $\begin{array}{l}\text { How often do you recommend } \\
\text { screening mammography for } \\
\text { most women ages... }\end{array}$ & $\begin{array}{c}\text { Every Year } \\
\mathbf{( 1 2} \text { months) }\end{array}$ & $\begin{array}{c}\text { Every Other } \\
\text { Year } \\
\text { (24 months) }\end{array}$ & $\begin{array}{c}\text { I discuss } \\
\text { interval } \\
\text { options with } \\
\text { the patient }\end{array}$ & $\begin{array}{c}\text { I Do Not } \\
\text { Routinely } \\
\text { Recommend }\end{array}$ \\
\hline $30-39$ years old & $12(3.2 \%)$ & $3(0.8 \%)$ & $20(5.3 \%)$ & $341(90.7 \%)$ \\
\hline $40-49$ years old & $122(31.9)$ & $32(8.4)$ & $202(52.9)$ & $26(6.8)$ \\
\hline $50-74$ years old & $249(65.4)$ & $80(21.0)$ & $50(13.1)$ & $2(0.5)$ \\
\hline $75+$ years old & $62(16.3)$ & $33(8.7)$ & $165(43.3)$ & $120(31.6)$ \\
\hline
\end{tabular}

2b. Cervical Cancer Screening:

Overall concordance across all age groups: $54.2 \%$

Screening in excess of the guidelines for at least one age group: $41.2 \%$

\begin{tabular}{|l|c|c|c|c|}
\hline $\begin{array}{l}\text { Approximately how often do } \\
\text { you recommend cervical } \\
\text { cancer screening for most } \\
\text { women ages... }\end{array}$ & $\begin{array}{c}\text { Pap alone } \\
\text { every 1 year }\end{array}$ & $\begin{array}{c}\text { Pap alone } \\
\text { every 3 } \\
\text { years }\end{array}$ & $\begin{array}{c}\text { Pap with HPV } \\
\text { co-testing } \\
\text { every 5 years }\end{array}$ & $\begin{array}{c}\text { I Do Not } \\
\text { Routinely } \\
\text { Recommend }\end{array}$ \\
\hline $\begin{array}{l}\text { Younger than 21 years who are } \\
\text { not sexually active }\end{array}$ & $3(0.80)$ & $5(1.3)$ & $3(0.8)$ & $365(97.1)$ \\
\hline $\begin{array}{l}\text { Younger than 21 years who are } \\
\text { sexually active }\end{array}$ & $38(10.2)$ & $22(5.9)$ & $17(4.6)$ & $294(79.3)$ \\
\hline 21 - 29 years old & $82(21.9)$ & $249(66.4)$ & $38(10.1)$ & $6(1.6)$ \\
\hline 30 - 64 years old & $9(2.4)$ & $69(18.5)$ & $291(78.0)$ & $4(1.1)$ \\
\hline $65+$ years old & $1(0.3)$ & $13(3.5)$ & $29(7.8)$ & $331(88.5)$ \\
\hline
\end{tabular}

Dark grey shading: concordant with the USPSTF guidelines.

Light grey shading: screening in excess of the USPSTF guidelines.

with the guidelines (14\%), malpractice risk (11\%), and inadequate time to discuss the benefits and harms of screening $(8 \%)$.

\section{Patient Requests for More Frequent Screening}

Providers noted that the majority of their patients ages 40 49 years asked to be screened with mammography before age 50 , and that the majority of patients ages 50-74 years asked to have annual rather than biennial mammography screening. In contrast, fewer women requested cervical cancer screening in excess of guidelines (Fig. 3).

\section{DISCUSSION}

Our study of primary care providers affiliated with four clinical networks in the northeastern United States found that a 
Table 3 Multivariate Correlates of Breast and Cervical Cancer Screening in Excess of the USPSTF Guideline Recommendations

In excess of USPSTF

recommendations:

\begin{tabular}{ll}
\hline $\begin{array}{l}\text { Breast cancer } \\
\text { screening }\end{array}$ & $\begin{array}{l}\text { Cervical cancer } \\
\text { screening }\end{array}$ \\
\cline { 1 - 2 } $\begin{array}{l}\text { Odds ratio (95\% } \% \\
\text { confidence interval) }\end{array}$ & \\
\hline
\end{tabular}

\begin{tabular}{|c|c|c|}
\hline \multicolumn{3}{|l|}{ Provider characteristics } \\
\hline \multicolumn{3}{|l|}{ Age: } \\
\hline$<40$ years & $1.74(0.75-4.02)$ & $0.44(0.22-0.89)$ \\
\hline $40-49$ years & $1.51(0.70-3.26)$ & $0.62(0.33-1.71)$ \\
\hline $50-59$ years & Reference & Reference \\
\hline $60+$ years & $1.52(0.61-3.79)$ & $0.77(0.37-1.60)$ \\
\hline \multicolumn{3}{|l|}{ Sex: } \\
\hline Female & Reference & Reference \\
\hline Male & $1.75(0.90-3.39)$ & $1.74(1.00-3.03)$ \\
\hline \multicolumn{3}{|l|}{ Provider specialty: } \\
\hline Family medicine & $0.96(0.46-2.0)$ & $0.53(0.28-1.03)$ \\
\hline (MD/ DO) & & \\
\hline General internal medicine & Reference & Reference \\
\hline Gynecology (MD/ DO) & $6.43(1.89-21.31)$ & $0.29(0.13-0.65)$ \\
\hline Physician assistant, nurse & $4.83(1.50-15.55)$ & $0.79(0.34-1.81)$ \\
\hline \multicolumn{3}{|l|}{$\begin{array}{l}\text { practitioner, certified nurse } \\
\text { midwife }\end{array}$} \\
\hline \multicolumn{3}{|c|}{ Typical week, no. of office visits } \\
\hline$<=25$ & $0.55(0.22-1.34)$ & $1.04(0.49-2.17)$ \\
\hline $26-50$ & $0.64(0.31-1.31)$ & $0.64(0.35-1.17)$ \\
\hline $51-75$ & Reference & Reference \\
\hline $76+$ & $1.74(0.68-4.45)$ & $1.17(0.60-2.31)$ \\
\hline \multicolumn{3}{|l|}{ Main practice characteristics } \\
\hline \multicolumn{3}{|l|}{ National Committee for Quality } \\
\hline \multicolumn{3}{|l|}{$\begin{array}{l}\text { Assurance (NCQA)-recognized } \\
\text { medical home }\end{array}$} \\
\hline No & $1.99(0.78-5.09)$ & $0.60(0.29-1.27)$ \\
\hline Yes & Reference & Reference \\
\hline \multicolumn{3}{|l|}{ Practice type: } \\
\hline Non-hospital-based office & Reference & Reference \\
\hline Hospital-based office & $0.36(0.18-0.74)$ & $0.52(0.29-0.94)$ \\
\hline Community health center & $0.29(0.09-0.92)$ & $0.71(0.26-1.94)$ \\
\hline \multicolumn{3}{|l|}{$\begin{array}{l}\text { Number of full- or part-time } \\
\text { physicians in practice }\end{array}$} \\
\hline$<5$ & $0.83(0.36-1.91)$ & $0.51(0.26-0.99)$ \\
\hline $5-10$ & Reference & Reference \\
\hline $11-20$ & $0.64(0.28-1.69)$ & $0.81(0.39-1.68)$ \\
\hline $21-50$ & $0.84(0.26-2.73)$ & $0.61(0.22-1.65)$ \\
\hline $50+$ & $0.78(0.18-3.46)$ & $0.42(0.12-1.39)$ \\
\hline
\end{tabular}

Models adjusted for provider age, sex, specialty, number of office visits per week, and practice characteristics including NCQA recognition as a medical home, practice type and size, and clinical network

majority of providers reported breast cancer screening practices in excess of those recommended in the 2009 USPSTF breast cancer guidelines, despite stating that these guidelines were very influential in their practice. Providers were more likely to report breast cancer than cervical cancer screening practices in excess of the guidelines. The Patient Protection and Affordable Care Act (ACA) requires health plans to cover screening tests with an " $\mathrm{A}$ " or " $\mathrm{B}$ " recommendation from the USPSTF. Of note, the ACA makes a special exception for mammography and requires coverage every 1 to 2 years for women beginning at age 40 . Our survey suggests that this exception is supported by the practices of providers, perhaps reflecting their perceived efficacy of mammography screening, patient preferences, and lack of consistency between performance measures and screening guidelines.

For breast cancer screening, much of the excess in use was attributable to continued use of annual screening for women ages 50-74 as well as ongoing regular screening for women ages 40-49 years. For cervical cancer screening, providers continued to screen women younger than age 21 if they were sexually active, and continued to offer annual screening to women in their 20s. Providers reported several reasons that their practices diverged from the recommendations, including their own disagreement with the guidelines, concerns expressed by patients about the guidelines, the use of conflicting performance measurement metrics, concerns about liability, and lack of time to discuss the benefits and harms of screening. These, often legitimate, concerns should be addressed to achieve guideline-consistent care. The greater concordance with USPSTF recommendations for cervical compared to breast cancer screening may be due to the lower level of controversy and the more broadly endorsed change in guidelines by other professional organizations. However, the use of screening for both cancer types continues to exceed guideline recommendations.

Our findings for provider reports of their use of breast cancer screening are similar to those of the 2012 survey of primary care providers conducted at the University of Pittsburgh. ${ }^{15}$ To our knowledge, no studies have examined provider reports of screening practices since the 2012 revision of the cervical cancer guidelines, and no surveys have asked how often patients request screening beyond guideline recommendations. Our findings showed greater concordance with the 2012 cervical guidelines, which recommend less frequent screening, compared to the 2009 breast guidelines. ${ }^{16}$ Interestingly, providers in our survey reported that USPSTF guidelines were most influential in their care, in contrast to an earlier nationally representative survey that found the ACS and ACOG guidelines to be most influential. ${ }^{20}$ As in prior studies, most providers in our survey valued multiple guidelines. ${ }^{20}$ To date, surveys of the cancer screening practices of primary care providers have focused on physicians; ${ }^{13-}$ 15,19 our sample included nurse practitioners, certified nurse midwives, and physician assistants, who are becoming more central to the provision of primary care as models of team-based care are disseminated. ${ }^{21}$ We examined a broader set of practice characteristics and found that providers who practiced in hospital-based settings were less likely to recommend screening in excess of both guidelines. 


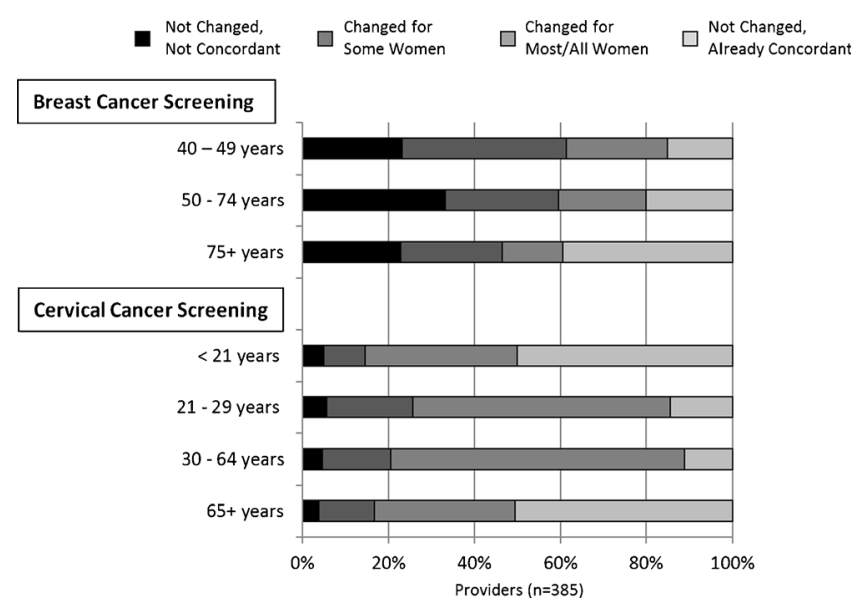

Fig. 2 Self-reported changes in screening recommendations since revised USPSTF recommendations. 2009 breast cancer screening recommendations; 2012 cervical cancer screening recommendations

Consistent with prior surveys regarding the cancer screening practices of primary care providers, we found evidence of "overuse," with providers recommending more frequent screening than that endorsed in USPSTF guidelines, as well as screening at the extremes of age. $^{13,22,23}$ Overuse of screening is expensive from societal and health system perspectives, as it may divert resources from other needed care and may result in unneeded follow-up evaluation and risk for individual patients. ${ }^{24,25}$ A recent analysis found that full adherence to USPSTF-recommended breast cancer screening strategies would save $\$ 4.4$ billion and would screen $15 \%$ more women than in current practice. ${ }^{24}$

This study has several limitations. Our sample is not nationally representative, and thus the generalizability of the results must be considered. Our sample was drawn from the northeastern U.S. and had a high proportion of providers affiliated with academic medical centers. There are no other multi-site studies that have examined this question, but our findings that providers do not follow the USPSTF guidelines are consistent with a single-site survey from Pittsburgh. ${ }^{15,16}$ More of our respondents were female compared to specialty-specific estimates reported by the Association of American Medical Colleges, but the age distribution was similar. ${ }^{26}$ We believe that a response rate of $58 \%$ is quite respectable for a provider survey. ${ }^{27}$

Our findings suggest ongoing controversy about, and inconsistent implementation of, the current USPSTF recommendations, particularly for breast cancer screening. This debate will continue, particularly in light of expected updates of USPSTF and ACS guidelines for breast cancer screening. It is imperative for guideline-issuing

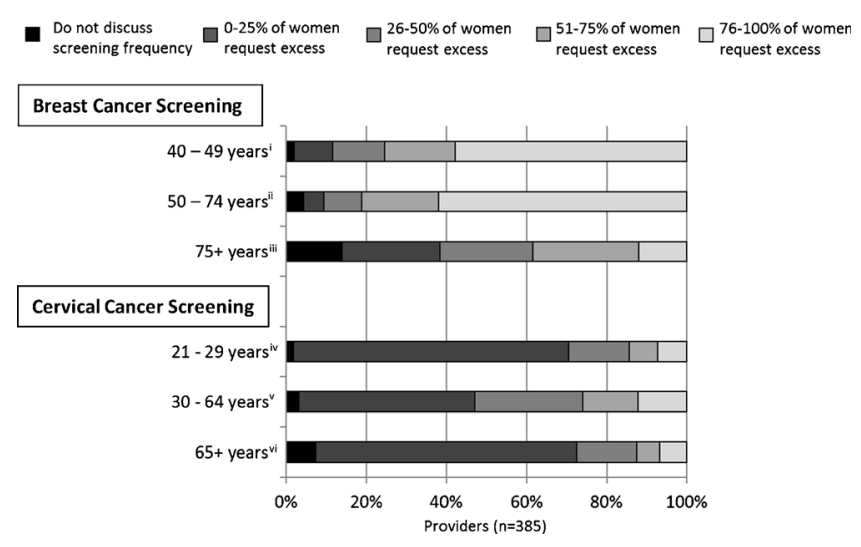

Fig. 3 Report of patient request to receive screening in excess of USPSTF recommendations. 2009 breast cancer screening recommendations; 2012 cervical cancer screening recommendations ${ }^{i}$ 'Excess' defined as any mammography before 50 'ii 'Excess' defined as annual screening iii 'Excess' defined as continuation of screening ${ }^{\text {iv }}$ 'Excess' defined as more than Pap testing every 3 years ${ }^{\mathrm{V}}$ 'Excess' defined as more than Pap and HPV co-testing every 5 years. ${ }^{\text {vi }}$ 'Excess' defined as continuation of Pap testing 
organizations to work with patient stakeholder groups and the media to ensure that patient concerns are addressed. The move toward accountable care also offers an opportunity to align cancer screening guidelines with payment reform. Finally, our findings point to the need for systems-based solutions to implementing cancer screening, as primary care providers lack the time, and likely the tools, to discuss the harms and benefits with individual patients. The growing use of population management programs may facilitate development of systems and tools to communicate the benefits and harms of screening outside the time constraints of a typical primary care visit. As guidelines become more individualized, further efforts should be made to ensure that they address the concerns of both providers and patients and are consistent with organizations' performance measurement metrics.

Acknowledgments: We appreciate the input of Alan Waxman, $M D$, on the development of the survey. This study was conducted as part of the National Cancer Institute-funded consortium, Population-based Research Optimizing Screening through Personalized Regimens (PROSPR) (grant numbers U54 CA163307, U54 CA 163313, U54 CA163303, U01CA163304, U54CA164336). A list of PROSPR investigators and contributing research staff is provided at: http://healthcaredelivery.cancer.gov/prospr/

Conflict of Interest: None of the authors have a conflict of interest.

Corresponding Author: Jennifer S. Haas, MD, MSc; Division of General Medicine and Primary CareBrigham and Women's Hospital, 1620 Tremont Street, Boston, MA 02120, USA (e-mail: jhaas@partners.org).

\section{REFERENCES}

1. Feldman S. Can the new cervical cancer screening and management guidelines be simplified? JAMA Intern Med. 2014.

2. Smith RA, Kerlikowske K, Miglioretti DL, Kalager M. Clinical decisions. Mammography screening for breast cancer. N Engl J Med. 2012;367, e31.

3. Nelson HD, Tyne K, Naik A, Bougatsos C, Chan BK, Humphrey L. Screening for breast cancer: an update for the U.S. Preventive services task force. Ann Intern Med. 2009;151:727-737.

4. Screening for breast cancer: U.S. Preventive services task force recommendation statement. Ann Intern Med 2009;151:716-726, W-236.

5. Mandelblatt JS, Cronin KA, Bailey S, Berry DA, de Koning HJ, Draisma G, Huang H, Lee SJ, Munsell M, Plevritis SK, Ravdin P, Schechter CB, Sigal B, Stoto MA, Stout NK, van Ravesteyn NT, Venier J, Zelen M, Feuer EJ. Effects of mammography screening under different screening schedules: model estimates of potential benefits and harms. Ann Intern Med. 2009; 151:738-47.

6. Smith RA, Manassaram-Baptiste D, Brooks D, Cokkinides V, Doroshenk M, Saslow D, Wender RC, Brawley OW. Cancer screening in the United States, 2014: a review of current American Cancer Society guidelines and current issues in cancer screening. CA: Cancer $\mathrm{J}$ Clin. 2014;64:30-51.

7. Practice bulletin no. 122: Breast cancer screening. Obstet Gynecol. $2011 ; 118: 372-82$.
8. Lee CH, Dershaw DD, Kopans D, Evans P, Monsees B, Monticciolo D, Brenner RJ, Bassett L, Berg W, Feig S, Hendrick E, Mendelson E, D'Orsi C, Sickles E, Burhenne LW. Breast cancer screening with imaging: recommendations from the Society of Breast Imaging and the ACR on the use of mammography, breast MRI, breast ultrasound, and other technologies for the detection of clinically occult breast cancer. J Am Coll Radiol: JACR. 2010;7:18-27.

9. Moyer VA. Screening for cervical cancer: U.S. Preventive services task force recommendation statement. Ann Intern Med. 2012.

10. ACOG. Practice bulletin number 131: Screening for cervical cancer. Obstet Gynecol. 2012;120:1222-238.

11. Yabroff KR, Zapka J, Klabunde CN, Yuan G, Buckman DW, Haggstrom D, Clauser SB, Miller J, Taplin SH. Systems strategies to support cancer screening in U.S. primary care practice. Cancer Epidemiol Biomarkers Prev. 2011;20:2471-479.

12. Sack K. Republicans Say Cancer Screening Guidelines Portend Medical Rationing. In: New York Times. New York: New York Times; 2009.

13. Saraiya M, Berkowitz Z, Yabroff KR, Wideroff L, Kobrin S, Benard V. Cervical cancer screening with both human papillomavirus and Papanicolaou testing vs Papanicolaou testing alone: what screening intervals are physicians recommending? Arch Intern Med. 2010;170:97785.

14. Meissner HI, Klabunde CN, Han PK, Benard VB, Breen N. Breast cancer screening beliefs, recommendations and practices: primary care physicians in the United States. Cancer. 2011;117:3101-11.

15. Corbelli J, Borrero S, Bonnema R, McNamara M, Kraemer $\mathbf{K}$, Rubio D, Karpov I, McNeil M. Physician adherence to U.S. Preventive services task force mammography guidelines. Womens Health Issues. 2014;24:e313-9.

16. Corbelli J, Borrero S, Bonnema R, McNamara M, Kraemer K, Rubio D, Karpov I, McNeil M. Differences among primary care physicians' adherence to 2009 ACOG guidelines for cervical cancer screening. J Womens Health (Larchmt). 2014;23:397-403.

17. Bodenheimer T, Pham HH. Primary care: current problems and proposed solutions. Health Aff. 2010;29:799-805.

18. Onega T, Beaber EF, Sprague BL, Barlow WE, Haas JS, Tosteson AN, Schnall MD, Armstrong K, Schapira MM, Geller B, Weaver DL, Conant EF. Breast cancer screening in an era of personalized regimens: a conceptual model and National Cancer Institute initiative for risk-based and preference-based approaches at a population level. Cancer. 2014;120(19):2955-64.

19. Meissner HI, Klabunde CN, Breen N, Zapka JM. Breast and colorectal cancer screening: U.S. primary care physicians' reports of barriers. Am J Prev Med. 2012;43:584-9.

20. Han PK, Klabunde CN, Breen N, Yuan G, Grauman A, Davis WW, Taplin SH. Multiple clinical practice guidelines for breast and cervical cancer screening: perceptions of US primary care physicians. Med Care. 2011;49:139-48.

21. Smith AA, Kepka D, Yabroff KR. Advanced practice registered nurses, physician assistants and cancer prevention and screening: a systematic review. BMC Health Serv Res. 2014;14:68.

22. Yabroff KR, Klabunde CN, Yuan G, McNeel TS, Brown ML, Casciotti D, Buckman DW, Taplin S. Are physicians' recommendations for colorectal cancer screening guideline-consistent? J Gen Intern Med. 2011;26:177-84.

23. Han PK, Klabunde CN, Noone AM, Earle CC, Ayanian JZ, Ganz PA, Virgo KS, Potosky AL. Physicians' beliefs about breast cancer surveillance testing are consistent with test overuse. Med Care. 2013;51:315-23.

24. O'Donoghue C, Eklund M, Ozanne EM, Esserman LJ. Aggregate cost of mammography screening in the United States: comparison of current practice and advocated guidelines. Ann Intern Med. 2014;160: 145.

25. Hubbard RA, Kerlikowske $\mathrm{K}$, Flowers CI, Yankaskas BC, Zhu W, Miglioretti DL. Cumulative probability of false-positive recall or biopsy recommendation after 10 years of screening mammography: a cohort study. Ann Intern Med. 2011;155:481-92.

26. 2012 Physician specialty data book; 2012 .

27. McLeod CC, Klabunde CN, Willis GB, Stark D. Health care provider surveys in the United States, 2000-2010: a review. Eval Health Prof. 2013;36:106-26. 